IGUSABDER, 5 (2018): 421-434

\title{
İnme Hastalarında Kinezyobantlamanın El Fonksiyonlarına Etkisi
}

\author{
Tuba Tülay KOCA*, Burhan Fatih KOÇYİĞİT ${ }^{* *}$, Burhan GÜÇMEN***, \\ Nurullah KELEŞ****
}

$\ddot{O} \mathbf{z}$

Amaç: Kas iskelet sistemi bozukluklarında kinezyobantlama (KT) sıklıkla kullanılmasına rağmen, inme hastalarında etkinliği hakkında yeterli veri yoktur. Birkaç çalışmada inme hastalarında KT'in alt ekstremite fonksiyonlarına, üst ekstremite lenfödem ve refleks sempatik distrofideki etkisi değerlendirilmiş fakat bildiğimiz kadarıyla el fonksiyonlarına etkisi üzerine ise çalışma yoktur. $\mathrm{Bu}$ çalışmamızın amacı hemiplejik hastalarda KT uygulamanın el fonksiyonlarına akut dönem etkisini değerlendirmektir.

Yöntem: Çalışmamıza son 1 yll içinde iskemik/hemorajik inme geçiren 20 hasta dâhil edildi. Tüm hastalara 3 gün süreli toplamda 3 kez önkol ekstansör kas bölgesine KT uygulaması yapıldı. Tüm hastaların demografik özellikleri (yaş, cinsiyet, eğitim, sigara kullanımı, diyabet (DM), hipertansiyon (HT), serebrovasküler hastalık tipi ve süresi, hemiplejik taraf, dominant el) kayıt edildi.

\footnotetext{
Özgün Araştırma Makalesi (Original Research Article)

Geliş / Received: 31.05.2018 \& Kabul / Accepted: 09.06.2018

* Dr. Öğr. Üyesi, Kahramanmaraş Sütçü İmam Üniversitesi, Tıp Fakültesi, Fiziksel Tıp ve Rehabilitasyon Anabilim Dalı, Kahramanmaraş, Türkiye, E-posta: tkoca@ksu.edu.tr ORCID ID https://orcid.org/0000-0002-4596-858X

${ }^{* *}$ Dr. Öğr. Üyesi, Kahramanmaraş Sütçü İmam Üniversitesi, Tıp Fakültesi, Fiziksel Tıp ve Rehabilitasyon Anabilim Dalı, Kahramanmaraş, Türkiye, E-posta: bfk2701@hotmail.com ORCID ID https://orcid.org/0000-0002-6065-8002

*** Ar. Gör., Kahramanmaraş Sütçü İmam Üniversitesi, Tıp Fakültesi, Fiziksel Tıp ve Rehabilitasyon Anabilim Dalı, Kahramanmaraş, Türkiye, E-posta: burhangucmen@hotmail.com ORCID ID https://orcid.org/oOoO-0002-1932-2128

**** Ar. Gör., Kahramanmaraş Sütçü İmam Ǘniversitesi, Tıp Fakültesi, Fiziksel Tıp ve Rehabilitasyon Anabilim Dalı, Kahramanmaraş, Türkiye, E-posta: dr.nknk@hotmail.com ORCID ID https://orcid.org/0000-0002-5443-060X
} 
Hastalığın şiddeti Ulusal Sağlık İnme Skalası (NIHSS) indeksi, el fonksiyonları uygulama öncesi ve sonrası (3. haftanın sonu) el fonksiyonel indeksi, iki aşamalı Minnesota el beceri testi (dokuz delikli test) ile el kavrama gücü ise dinamometre ile değerlendirildi.

Bulgular: Çalışmaya ortalama $61 \pm 6$ yaşlarında 13 erkek, 7 kadın hasta dâhil edildi. Hastaların \%45’i 3 aydan kısa süreli tanı almıştı, \%10o HT, \%85 DM hastası idi. İnme tiplerinden en sık \%9o ile iskemik tipi görüldü. Tutulan taraf sağ ve sol eşit oranda idi.

Hastaların tedavi öncesi ve 3 haftalık KT uygulaması sonrası el kavrama gücü ( $p=0,001)$, el fonksiyonel indeksi $(\mathrm{p}=\mathrm{o}, \mathrm{oo})$ ve dokuz delikli test süresinde $(\mathrm{p}=0,001)$ anlamlı farklılı gözlendi.

Sonuç: KT uygulaması inme rehabilitasyonunda akut dönemde el fonksiyonlarına olumlu etkide bulunmaktadır.

Anahtar Sözcükler: İnme, kinezyobantlama, rehabilitasyon, üst ekstremite.

\title{
Effect of Kinesiotape on Hand Functions in Stroke Patients
}

\begin{abstract}
Aim: Despite the frequent use of kinesiotape (KT) in musculoskeletal disorders, there is insufficient data on its effectiveness in stroke patients. Several studies have evaluated the effect of KT on lower extremity functions, upper limb lymphedema and reflex sympathetic dystrophy in stroke patients, but as far as we know there is no study evaluating its effects on hand functions. The purpose of this study is to evaluate the acute phase effect on hand function of KT application in hemiplegic patients.

Method: Twenty patients who had an ischemic / hemorrhagic stroke within the last 1 year were included into the study. All patients were treated with KT application to the forearm extensor muscle region, 3 times in total for 3 days. All patients' demographic characteristics [age, gender, education, smoking, diabetes (DM), hypertension (HT), type and duration of cerebrovascular disease, hemiplegic side, dominant hand] were recorded.

The severity of the disease was assessed by the National Health Stroke Scale (NIHSS) index, hand functions were assessed by two-step Minnesota hand skill test (nine-hole test), hand functional index before and after KT application (end of 3 rd week ) and hand grip strength by dynamometer.
\end{abstract}

Findings: Thirteen male and seven female patients were included in the study at an average age of $61 \pm 6$ years. $45 \%$ of the patients had a short duration diagnosis of 3 months, $100 \%$ had 
HT, 85\% had DM. Ischemic type was the most frequently seen stroke types with a frequency of 90\%. Significant differences were observed in hand grip strength $(\mathrm{p}=0.001)$, hand functional index $(\mathrm{p}<0.001)$ and nine-hole test duration $(\mathrm{p}=\mathrm{o.001})$ after 3 weeks of KT application.

Conclusion: KT has a positive effect on hand functions in the acute phase in stroke rehabilitation.

Keywords: Stroke, kinesiotape, rehabilitation, upper extremity.

\section{Giriş}

Kinezyobant (KT); kan ve lenfatik akışı artırmak yoluyla, kas ve eklem yaralanmalarında ağrıyı azaltmak için kompresyonun hafifletilmesi ile cildi yükselten elastik bandajdır. KT ile ilgili uygulama yönü, süresi, frekansı ve gerginlik derecesi henüz bir protokol üretmek için yeterli ayrıntıda tanımlanmamıştır. KT uygulaması ağrı veya işlev bozukluğu alanlarına elastik bir yapışkan bant yerleştirilmesini içerir. Etki mekanizmaları, her ikisi içinde lokal dolaşımı arttıran duyusal afferentlerin stimülasyonu yoluyla eklem hareket açıklığının güçlendirilmesi ve ağrının azaltılmasını içerir $^{1,2}$.

İnme; beyin kan akımının çeşitli sebeplere bağlı olarak ani olarak kesilmesi ile ortaya çıkan ve nörolojik fonksiyon bozukluğuna yol açan bir sendromdur. İnme, mortalitenin üçüncü en yaygın nedeni ve yetişkinlerin fiziksel engelliliğinin başlıca nedenlerinden biridir. Tüm inmeler içinde iskemik inme \%75-80, intraserebral hemoraji \%10-15, subaraknoid kanama \%5-10 oranında görülmektedir³.

İnme rehabilitasyonunun amacı, hastanın beynin etkilenen kısmına göre kaybedilen becerileri öğrenmesine yardımcı olmaktır. İnme rehabilitasyonu, bağımsızlığı yeniden kazanmayı ve yaşam kalitesini iyileştirmeyi amaçlar.

Kas iskelet sistemi bozukluklarında KT'nin sıklıkla kullanılmasına rağmen, inme hastalarında etkinliği hakkında yeterli veri yoktur. Birkaç çalışmada inme hastalarında KT'in alt ekstremite fonksiyonlarına, üst ekstremite lenfödem ve refleks sempatik distrofideki etkisi değerlendirilmiş fakat bilindiği kadarıyla el fonksiyonlarına etkisi üzerine çalışma yoktur. Bu çalışmanın amacı hemiplejik hastalarda KT uygulamanın el fonksiyonlarına akut dönem etkisini değerlendirmektir. 


\section{Gereç ve Yöntem}

Çalışmamıza son 1 yll içinde iskemik/hemorajik inme geçiren 20 hasta dahil edildi. Tüm hastalara 3 gün süreli toplamda 3 kez önkol ekstansör kas bölgesine KT uygulaması yapıldı. Tüm hastaların demografik özellikleri [yaş, cinsiyet, eğitim, sigara kullanımı, diyabet (DM), hipertansiyon (HT), serebrovasküler hastalık tipi ve süresi, hemiplejik taraf, dominant el] kayıt edildi.

Hastalığın şiddeti Ulusal Sağlık İnme Skalası (NIHSS) indeksi ile (NIH değeri 10 puanın altında alanlar "hafif inmeli", 11 ve üzerinde puan alanlar "ağır inmeli" olarak kabul edildi) el fonksiyonları ise uygulama öncesi ve sonrası (3. haftanın sonu) el fonksiyonel indeksi, iki aşamalı Minnesota el beceri testi (dokuz delikli test) ve el kavrama gücü dinamometre ile değerlendirildi.

Akut cilt enfeksiyonu, açık yaralar, ven trombozu, frajil cilt, üst ekstremite kırık, tutulan tarafta omuz veya dirsek patolojisi, konuşma problemi, dekompanse sistemik problemli (kalp, karaciğer yetmezliği) olan hastalar çalışmaya dâhil edilmedi.

\section{İstatistik}

İstatistik analizleri için SPSS 17 (Windows için SPSS İstatistikleri, Sürüm 17.o, Şikago: SPSS Inc., ABD) kullanılmıştır. Çalışmanın yaş ve cinsiyet değerleri ortalama ve standart sapma olarak verilmiştir. Aynı bireyin değişkenlerini karşılaştırmak için eşleştirilmiş örneklem $\mathrm{t}$ testi kullanıldı, veri analizi için tanımlayıcı testler uygulanmıştır. Parametrik olarak dağılmayan değişkenler için medyanların karşılaştırılması için Mann-Whitney U testi kullanılmıştır. İstatistiksel eşik p <0.005 olarak kabul edilmiştir. Çalışma için lokal etik kurul onayı alınmıştır (no:154) ve Helsinki deklerasyon prensiplerine uyulmuştur.

\section{KT Uygulama Tekniği}

KT uygulanmadan önce cilt temizliği gerçekleştirildi. KT'nin uygulanması, Şekil 1'de gösterildiği şekilde aynı sağlık uzmanı tarafından gerçekleştirildi. Ortalama olarak 30 cm'lik (Tmax kinesiology tape ve Tmax medical, Güney Kore) bir tip I bandı lateral epikondil bölgesinden metakarpallerin sonuna kadar, \%15-25 gerim ile elin dorsal yüzüne, bantlama yönü fasilitasyon tekniği ile (başlangıç yönü kasın orjin noktası olacak şekilde) yapıldı. Bandın yapışma yerlerine sıfır gerim (\% o) uygulandı. Uygulamadan sonra hafif ısı ve basınç ile bandın iyi yapışması sağlandı. 
Şekil 1: Ön kol ekstansör yüze KT uygulama şekli

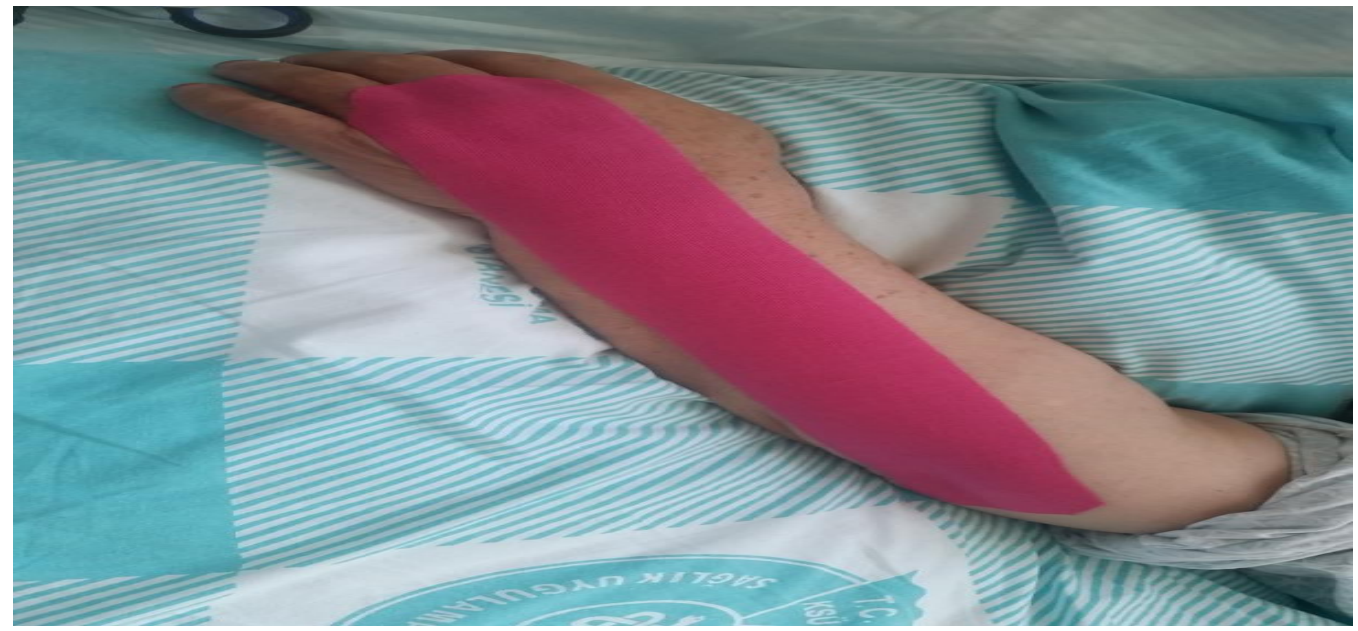

\section{Ulusal Sağlık İnme Skalası (NIHSS)}

Ulusal Sağlı İnme Skalası (NIHSS) nörologlar arasında yaygın olarak kullanılmaktadır. En sık akut iskemik inme ile birlikte kullanılır, ancak hemorajik inme veya geçici iskemik atak şüphesi sonrası hastaları değerlendirmek için de kullanılır. NIHSS 15 maddelik bir ölçektir. İçeriğinde konuşma, dil, biliş, dikkatsizlik, görme alanı bozuklukları, motor güç, duyusal bozukluk, ataksi ve bilinç düzeyini değerlendiren kademeli fizik muayeneyi içerir4. Yüksek skorlar hastalığın şiddetini işaret eder.

\section{Dinamometre}

El kavrama güçleri Jamar dinamometre ile ölçüldü. Ölçüm hasta oturur pozisyonda, dirseğini masaya dayarken, omuz adduksiyon ve nötral rotasyonda, dirsek 90 derece fleksiyonda, ön kol ve el bileği nötral pozisyonda olmak üzere yapıldı. Hastalara tüm ölçümler üç kere yapıldı ve ortalama değerleri alındı. Ölçümler kilogram cinsinden hesaplandı ve tüm hastalarda aynı genişlik kullanıldı.

\section{Minnesota El Becerisi Testi}

Minnesota Manual Dexterity Testi, basit fakat hızlı göz el parmak hareketinin yanı sıra el kol hareketleri ve brüt motor becerilerini değerlendirmek için de etkilidir. Brüt motor becerilerini ölçerken hareket hassasiyeti, becerinin başarılı bir şekilde uygulanması kadar önemli değildir. 4 farklı test içerir; yerleştirme, döndürme, yer değiştirme, bir elle çevirme ve yerleştirme testi. Burada birinci ve dördüncü aşamaları dokuz delikli 
tahta aracılığıyla uyguladık5,6. Yerleştirme testi bir kişinin baskın elini kullanarak üst panelden alttaki diskleri koyabileceği hızı değerlendirmek için kullanılır.

\section{Brunstrom Motor Evreleme}

Evre 1: El flasktır. İstemli motor aktivite yoktur.

Evre 2: Parmaklarda hafif fleksiyon hareketi başlamıştır.

Evre 3: Elde kaba ve çengel kavrama başlamıştır, ancak istemli parmak ekstansiyonu ve gevşeme olmaz. Ara ara parmaklarda refleks ekstansiyon hareketi görülebilir.

Evre 4: Başparmak hareketleri ile lateral kavrama başlamıştır. Küçük açılarda kısmen istemli kabul edilebilecek parmak ekstansiyonu görülür.

Evre 5: Tam istemli ve kontrollü olmamakla birlikte silindirik ya da sferik parmak kavramaları başlamıştır. Değişik açılarda istemli parmak ekstansiyonu izlenir.

Evre 6: Tüm kavramalarda kontrol kazanılır, parmaklarda tam ekstansiyon yapılabilir, normale yakın ele nazaran beceriler sınırlı olabilir.

\section{Bulgular}

Çalışmaya ortalama $61 \pm 6$ yaşlarında 13 erkek, 7 kadın hasta dâhil edildi. Hastaların \%45’i 3 aydan kısa süreli tanı almıştı, \%85 sigara içicisi, \%10o HT, \%85 DM hastası idi. İnme tiplerinden en sı \%9o ile iskemik tipi (aterosklerotik, kardiyoembolik) görüldü. Tutulan taraf sağ ve sol eşit oranda idi. Hastalara ait tanımlayıcı veriler Tablo 1'de özetlenmektedir.

Tablo 1: Hastalara ait tanımlayıcı özellikler

\begin{tabular}{|l|l|l|}
\hline & \multicolumn{2}{|l|}{ Ortalama \pm std } \\
\hline Yaş (yıl) & $61 \pm 6$ \\
\hline Cinsiyet (K/E) & $13 / 7$ \\
\hline Dominant el (să̆/sol) & $20 / 0$ \\
\hline Tutulan taraf (sağ/sol) & $10 / 10$ & \% \\
\hline & $\mathbf{n = 2 0}$ & \\
\hline Ĕ̆itim düzeyi & 5 & 25 \\
Okur-yazar değil & 55 \\
İlk-orta & 13 & 10 \\
Lise & 2 & \\
\hline
\end{tabular}




\begin{tabular}{|l|c|c|}
\hline İnme tipi & & \\
İskemik & 18 & 90 \\
Hemorajik & 2 & 10 \\
\hline Sigara & 3 & 15 \\
\hline Diyabet mellitus & 17 & 85 \\
\hline Hipertansiyon & 20 & 100 \\
\hline
\end{tabular}

Hastaların NIH inme skalası, el düzeyinde Brunnstrom seviyeleri, spastisite düzeyleri ile 3 haftalık program öncesi ve sonrası el fonksiyon indeksi, el kavrama gücü, dokuz delikli testleri ortalama değerleri Tablo 2'de verildi. Hastaların tedavi öncesi ve 3 haftalık KT uygulaması sonrası el kavrama gücü $(\mathrm{p}=0,001)$, el fonksiyonel indeksi $(\mathrm{p}=\mathrm{o}, \mathrm{oo})$ ve dokuz delikli test süresinde $(\mathrm{p}=\mathrm{0}, \mathrm{oo1})$ anlamlı farklılık gözlendi. Hiçbir hastada KT uygulaması sonrası cilt reaksiyonu gelişmedi. Grubu NIHSS'e göre hafif ve ağır inmeli olarak ikiye ayırdığımızda hafif gruptaki hasta sayısı 16, ağır gruptaki hasta sayısı 4 idi. Gruplar sayı olarak farklılık gösterdiğinden istatistiksel karşılaştırma yapılmadi.

Tablo 2: Hastaların nörolojik muayeneleri ve fonksiyonel düzeylerini ölçen skala verileri

\begin{tabular}{|l|c|}
\hline & N / \% \\
\hline Brunnstrom (el) & $7 / 35$ \\
1 & $5 / 25$ \\
2 & - \\
4 & - \\
5 & $8 / 40$ \\
6 & - \\
\hline Ashworth spastisite skoru (el) & $11 / 55$ \\
0 & $6 / 30$ \\
1 & $3 / 15$ \\
2 & \\
\hline
\end{tabular}




\begin{tabular}{|l|c|}
\hline 3 & - \\
\hline & - \\
\hline NIHHSS & Ortalama \pm std \\
\hline El kavrama gücü (kg) & $3,4 \pm 2,8$ \\
\hline KT öncesi & $13 \pm 11,5$ \\
KT sonrası & $18,8 \pm 11,5$ \\
$p^{*}$ & 0.001 \\
\hline El fonksiyon indeksi skor & \\
& \\
KT öncesi & $10,6 \pm 7,7$ \\
KT sonrası & $6,1 \pm 1,5$ \\
$p^{*}$ & $<0.001$ \\
\hline Dokuz delikli test (sn) & \\
KT öncesi & $114,8 \pm 39,1$ \\
KT sonrası & $95,3 \pm 38,5$ \\
$p^{*}$ & $<0.001$ \\
\hline Kaltmalar: NIHSS: & \\
\hline
\end{tabular}

Kısaltmalar: NIHSS: Ulusal Sağlık İnme Skalası; KT: Kinezyobant

${ }^{*} p<0.005$ istatiksel olarak anlamlı kabul edilmiştir.

\section{Tartışma}

İnme, gelişmiş ülkelerde kalp hastalığı ve kanserden sonra üçüncü sıradaki ölüm nedenidir. Dünya Sağlık Örgütü (DSÖ) tanımlamasına göre, inme vasküler nedenler dışında görünür bir neden olmaksızın, beyin kan akımının bozulması sonucunda fokal serebral fonksiyon kaybına ait belirti ve bulguların hızla yerleşmesi ve bu bulguların 24 saat ve daha uzun sürmesi ile karakterize klinik bir sendromdur. Rehabilitasyonun inme hastalarında özürlülük seviyesini azaltmada yaygın olarak kullanıldığı bilinmektedir. Rehabilitasyon uygulamalarına hastanın tıbbi durumu stabil olur olmaz başlanması önerilmektedir? . 
İnme sonrası üst ekstremite genellikle alt ekstremiteye göre daha çok etkilenir. Üstelik inme sonrası motor iyileşmede üst ekstremitenin daha zayıf olduğu bildirilmiştir. Bununla birlikte günlük yaşam aktivitelerinin yerine getirilmesinde üst ekstremite fonksiyonları önemli yer tutar. Zamanla gelişen iyileşmeyle beraber değişik faktörlere bağlı olarak sağ kalan inmeli bireylerin bağımsız olarak yürüyebilme şansı \%82 iken, üst ekstremitesini fonksiyonel kullanabilme şansları \%50'dir ${ }^{8,9}$.

Bir kayroprak olan Dr. Kenso Kase tarafindan 1970'lerde geliştirilen KT, eklem hareketini kısıtlamaksızın kas iskelet sisteminin yapılarını destekleyerek vücudun doğal iyileşme sürecine yardımcı olmak için cilde uygulanır. KT, kan ve lenfatik akışı iyileştirmek ve böylece kas ve eklem yaralanmalarındaki ağrıları azaltmak için cildi kaldırarak etkinliğini gösterir. KT'nin etkisi, derideki gerginlikle ilgilidir ${ }^{10}$. KT kişisel bir ürün olarak piyasaya sürülür. Yapısını \%10o pamuklu elyaflarla sarılmış polimer elastik lifler oluşturur. Yapışkan, \%100 akrilik ve ısı ile aktive edilmiştir. Akrilik yapıştırııı, parmak izi benzeri, dalgalı bir desene sahiptir ${ }^{11}$.

KT nörolojik hastalarda amprik fayda sağlayan tamamlayıcı bir teknik olarak karşımıza çıkmaktadır. Bununla birlikte literatüre baktığımızda KT etkinliğine dair daha kaliteli metodolojik çalışmalara ihtiyaç vardır ${ }^{12}$. KT’nin üst ekstremite rahatsızlıklarında etkinliğini destekleyen az sayıda delil vardır ${ }^{13,14}$. Ayrıca literatürde KT'in diğer modalitelere üstünlüğüne dair destekleyici veri yeterli değildir.

Romatoid Artrit'li hastalara KT uygulaması sonucu standard fizyoterapiye göre el kas gücünde anlamlı yükselme gözlenmiştiri5. Önkol dorsal yüze gerimsiz KT uygulaması, intersection sendromu tedavisinde semptomların azalmasına neden olarak başarılı olmuştur ${ }^{16}$. Bir diğer çalışmada sağlıklı atletlerde önkol KT’nin, maksimal yakalama kuvvetinde değişikliğe sebep olmadığı görülmüşş7. Köseoğlu ve ark..$^{18}$ inme hastalarında tibialis anterior bölgesine KT uygulamasının alt ekstremite motor iyileşmeye, spastisiteye, ambulasyon kapasitesine, yaşam kalitesi ve yürüyüşe katkı sağladığı gösterilmiş. İnme hastalarında quadriceps kasına konvansiyonel rehabilitasyon programına ek olarak KT uygulanması fonksiyonel parametrelerde değil izokinetik test parametrelerinde efektif olarak bulunmuş ${ }^{19}$.

Huang YC ve ark.20, hemiplejik omuzda yapmış olduğu çalışmada 3 haftalık KT grubunda omuz ağrı ve disabilite indeksinde daha fazla düşme; omuz fleksiyon, internal ve eksternal rotasyonunda daha fazla iyileşme gözlenmiştir. Kalichman ve 
ark. ${ }^{21}$, benzer şekilde hemiplejik omuza KT uygulamaları sonrası kısa vadede KT herhangi bir parametrede değişime neden olmamıştır. Lee DH ve ark. ${ }^{22}$, KT uygulama ile verilen görevleri başarmada hemiparetik tarafda daha hızlı, kolay ve başarılı bir uzanma hareket paterni gözlenmiştir. İnme sonrası üst ekstremitede kompleks bölgesel ağrı sendromu gelişen hastalarda da KT uygulamanın klasik fizyoterapi yöntemlerine katkı sağlayabildiği gözlenmiştir²3.

KT'in hemiplejik hastalarda proprioseptif duyu stimulasyonuna olumlu etki ile yürüyüş sırasındaki deviasyonlarda azalma gözlenmiştir ${ }^{24}$. KT’ın kas kuvveti üzerine etkisi henüz bilinmemektedir. Karahan AY ve arkadaşlarının²5 yaptıkları çalışmada triceps kasına Y şeklinde KT uygulamanın kas gücüne olumlu etkisi gösterilmemiştir. Sensorimotor bozukluklarda fasilitator veya inhibitör KT uygulama yoğun tekrarlayıcı egzersiz programına ek olarak fayda sağlayabildiği gösterilmiştir ${ }^{26}$. Birden fazla çalışmada lateral epikondilit hastalarında KT uygulama ile ağrı, fonksiyonel durum ve el kavrama gücünde belirgin iyileşme gözlenmiştir ${ }^{27}$. Rigoldi C ve ark..28, Down sendromlu 5 hastada yaptığı çalışmada nöromuskuler KT ile propriosepsiyonu olumlu yönde modifiye ederek, disgrafi ve el koordinasyonu tedavisinde efektif bulunmuştur. Serebral palsili çocuklara tenar KT uygulaması ile başparmak repozisyonlaması ve el fonksiyonlarına olumlu katkısı gösterilmiştir29.

Genç sağlıklı bireylerde KT uygulamanın tekrarlayıcı, izokron el bilek fleksiyonekstansiyon hareketlerindeki variabiliteyi azalttığı ve kutenöz mekanoreseptör aktivasyonuyla ekstra proprioseptif bilgi sağladığı görülmüştür3․ KT karpometakarpal eklem osteoartritin konservatif tedavisinde eklem mobilizasyonunda başarılı bulunmuştur ${ }^{30}$. İnme hastalarında omuz impingement sendromunda KT uygulama fizyoterapiye göre ağrı ve engellilik parametrelerinde ilk haftada daha başarılı iken, 2. haftada benzer etkili bulunmuştur ${ }^{31}$.

Çalışmamızda KT uygulaması sonrası hemiplejik taraf el fonksiyonlarında ve kas gücünde 3 uygulama sonrası anlamlı iyileşme gözlenmiştir. Çalışmamızın değerlendirmesi tedaviyi hemen takiben yapılmıştır.

\section{Çalışmanın Limitasyonu}

Çalışmaya alınan hastaların büyük bölümü akut dönemdedir. Akut dönemde iyileşme düzeyleri inmeli hastalarda en yüksek ilk 3 ayda olmakla birlikte 1 yıla kadar devam 
eder. Akut dönemde el bölgesindeki uygulamanın değerlendirilmesi zordur. Bunun yanında el fonksiyonları en son iyileşmenin görüldüğü bölgedir.

\section{Sonuç}

KT uygulaması inme rehabilitasyonunda akut dönemde el fonksiyonlarına yan etki olmaksızın olumlu etkide bulunmaktadır. KT akut dönem sonuçları iyi olmakla birlikte uzun vadeli sonuçlarına ait randomize kontrollü çalışmalara ihtiyaç vardır.

\section{KAYNAKLAR}

1. Williams S, Whatman C, Hume PA, Sheerin K. Kinesio taping in treatment and prevention of sports injuries: a meta-analysis of the evidence for its effectiveness. Sports Med. 2012;42(2):153-164. doi: 10.2165/11594960000000000-00000.

2. Anandkumar S. Kinesio tape management for superficial radial nerve entrapment: a case report. Physiother Theory Pract. 2013;29(3):232-241. doi:10.3109/09593985.2012.717589.

3. Bell A, Muller M. Effects of kinesio tape to reduce hand edema in acute stroke. Top Stroke Rehabil. 2013;20(3):283-288. doi: 10.1310/tsr2003-283.

4. Meyer BC, Hemmen TM, Jackson CM, Lyden PD. Modified National Institutes of Health Stroke Scale for use in stroke clinical trials: prospective reliability and validity. Stroke. 2002;33(5):1261-1266.

5. Tesio L, Simone A, Zebellin G, Rota V, Malfitano C, Perucca L. Bimanual dexterity assessment: validation of a revised form of the turning subtest from the Minnesota Dexterity Test. Int $J$ Rehabil Res. 2016;39(1):57-62. doi: 10.1097/MRR.ooooooooooooo145.

6. Surrey LR, Nelson K, Delelio C, et al. A comparison of performance outcomes between the Minnesota Rate of Manipulation Test and the Minnesota Manual Dexterity Test. Work. 2003;20(2):97-102.

7. Craig LE, Wu O, Bernhardt J, Langhorne P. Approaches to economic evaluations of stroke rehabilitation. Int J Stroke. 2014;9(1):88-100. doi: 10.1111/ijs.12041. 
8. Richards CL, Malouin F, Nadeau S. Stroke rehabilitation: clinical picture, assessment, and therapeutic challenge. Prog Brain Res. 2015;218:253-280. doi: 10.1016/bs.pbr.2015.01.003.

9. İnanç Y, Arlıer Z, Giray S, İnanç Y. Demographic characteristics of patients who recovered or worsened after intravenous thrombolysis within 24 hours of acute ischemic stroke. Neurol Sci Neurophysiol. 2018;35:29-33.

10. Pizac DA, Swanik CB, Glutting JJ, Kaminski TW. Evaluating postural control and ankle laxity between taping and high-top cleats in high school football players. J Sport Rehabil. 2018;27(2):111-117.

11. Morris D, Jones D, Ryan H, Ryan CG. The clinical effects of Kinesio® Tex taping: A systematic review. Physiother Theory Pract. 2013;29(4):259-270. doi: 10.3109/09593985.2012.731675.

12. Ortiz-Ramirez J, Perez-De la Cruz S. [Efficacy of the application of kinesio tape in patients with stroke]. Rev Neurol. 2017;64(4):175-179.

13. Taylor RL, O'Brien L, Brown T. A scoping review of the use of elastic therapeutic tape for neck or upper extremity conditions. $J$ Hand Ther. 2014;27(3):235-245. doi: 10.1016/j.jht.2014.03.004.

14. Mostafavifar M, Wertz J, Borchers J. A systematic review of the effectiveness of kinesio taping for musculoskeletal injury. Phys Sportsmed. 2012;40(4):33-40. doi: 10.3810/psm.2012.11.1986.

15. Szczegielniak J, Łuniewski J, Bogacz K, Sliwiński Z. The use of kinesiology taping method in patients with rheumatoid hand--pilot study. Ortop Traumatol Rehabil. 2012;14(1):23-30.

16. Kaneko S, Takasaki H. Forearm pain, diagnosed as intersection syndrome, managed by taping: a case series. J Orthop Sports Phys Ther. 2011;41(7):514519. doi: 10.2519/jospt.2011.3569.

17. Chang HY, Chou KY, Lin JJ, Lin CF, Wang CH. Immediate effect of forearm Kinesio taping on maximal grip strength and force sense in healthy collegiate athletes. Phys Ther Sport. 2010;11(4):122-127. doi: 10.1016/j.ptsp.2010.06.007.

18. Koseoglu BF, Dogan A, Tatli HU, Sezgin Ozcan D, Polat CS. Can kinesio tape be used as an ankle training method in the rehabilitation of the stroke patients? Complement Ther Clin Pract. 2017;27:46-51. doi: 10.1016/j.ctcp.2017.03.002.

19. Ekiz T, Aslan MD, Özgirgin N. Effects of Kinesio Tape application to quadriceps muscles on isokinetic muscle strength, gait, and functional parameters in 
patients with stroke. $J$ Rehabil Res Dev. 2015;52(3):323-331. doi: 10.1682/JRRD.2014.10.0243.

20. Huang YC, Chang KH, Liou TH, Cheng CW, Lin LF, Huang SW. Effects of Kinesio taping for stroke patients with hemiplegic shoulder pain: A doubleblind, randomized, placebo-controlled study. J Rehabil Med. 2017;49(3):208215. doi: 10.2340/16501977-2197.

21. Kalichman L, Frenkel-Toledo S, Vered E, et al. Effect of kinesio tape application on hemiplegic shoulder pain and motor ability: a pilot study. Int $J$ Rehabil Res. 2016;39(3):272-276. doi: 10.1097/MRR.0ooooooooooo0167.

22. Lee DH, Kim WJ, Oh JS, Chang M. Taping of the elbow extensor muscle in chronic stroke patients: comparison between before and after threedimensional motion analysis. J Phys Ther Sci. 2015;27(7):2101-2103. doi: 10.1589/jpts.27.2101.

23. Anandkumar S, Manivasagam M. Multimodal physical therapy management of a 48-year-old female with post-stroke complex regional pain syndrome. Physiother Theory Pract. 2014;30(1):38-48. doi: 10.3109/09593985.2013.814186.

24. Park YH, Lee JH. Effects of proprioceptive sense-based Kinesio taping on walking imbalance. $J$ Phys Ther Sci. 2016;28(11):3060-3062. doi: 10.3109/09593985.2012.731675.

25. Karahan AY, Yildirim P, Kucuksarac S, et al. Effect of Kinesio taping on elbow muscle strength in healthy individuals: A randomized trial 1. J Back Musculoskelet Rehabil. 2017;30(2):317-323. doi: 10.3233/BMR-160529.

26. Bravi R, Cohen EJ, Quarta E, Martinelli A, Minciacchi D. Effect of direction and tension of kinesio taping application on sensorimotor coordination. Int J Sports Med. 2016;37(11):909-914. doi: 10.1055/s-0042-109777.

27. Dilek B, Batmaz I, Sarıyıldız MA, et al. Kinesio taping in patients with lateral epicondylitis. J Back Musculoskelet Rehabil. 2016;29(4):853-858.

28. Rigoldi C, Galli M, Celletti C, Blow D, Camerota F, Albertini G. Does neuromuscular taping influence hand kinesiology? A pilot study on Down's Syndrome. Clin Ter. 2015;166(4):257-263. doi: 10.7417/T.2015.1870.

29. Keklicek H, Uygur F, Yakut Y. Effects of taping the hand in children with cerebral palsy. J Hand Ther. 2015;28(1):27-32. doi: 10.1016/j.jht.2014.09.007. 
30. Bravi R, Quarta E, Cohen EJ, Gottard A, Minciacchi D. A little elastic for a better performance: kinesiotaping of the motor effector modulates neural mechanisms for rhythmic movements. Front Syst Neurosci. 2014;8:181. doi: 10.3389/fnsys.2014.00181.

31. Villafañe JH, Valdes K. Mobilization with movement and elastic tape application for the conservative management of carpometacarpal joint osteoarthritis. $J$ Hand Ther. 2015;28(1):82-84. doi: 10.1016/j.jht.2014.08.001.

32. Kaya E, Zinnuroglu M, Tugcu I. Kinesio taping compared to physical therapy modalities for the treatment of shoulder impingement syndrome. Clin Rheumatol. 2011;30(2):201-207. doi: 10.1007/s10067-010-1475-6. 